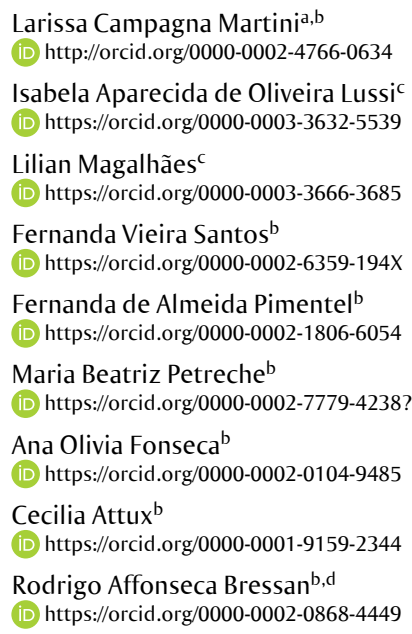

a Universidade Federal de São Carlos (UFSCar), Departamento de Medicina. São Carlos, SP, Brasil.

b Universidade Federal de São Paulo (Unifesp), Departamento de Psiquiatria. São Paulo, SP, Brasil.

' Universidade Federal de São Carlos (UFSCar), Departamento de Terapia Ocupacional. São Carlos, SP, Brasil.

d Y-Mind - Instituto de Prevenção e Tratamento de Transtornos Mentais. São Paulo, SP, Brasil.

Contato:

Larissa Campagna Martini

E-mail:

larissacmb@ufscar.br

Trabalho baseado na tese de doutorado Desafios para a reinserção profissional de pessoas com esquizofrenia, apresentada por Larissa Campagna Martini ao Programa de Pós-Graduação em Psiquiatria e Psicologia Médica da Universidade Federal de São Paulo em 2017.

Os autores declaram que o trabalho não foi subvencionado e que não há conflitos de interesses.

Os autores informam que o estudo não foi apresentado em evento científico.

Recebido: 16/05/2017

Revisado: 16/10/2017

Aprovado: 16/09/2018

\section{Experiência laboral e inclusão social de indivíduos com esquizofrenia}

\author{
Work experience and social inclusion \\ of individuals with schizophrenia
}

\section{Resumo}

Objetivos: compreender os aspectos positivos e negativos das experiências relacionadas ao trabalho relatadas por indivíduos com esquizofrenia, usuários de um ambulatório de especialidades envolvido em um programa de inclusão laboral. Métodos: estudo com abordagem qualitativa e observacional. Onze participantes responderam a uma pergunta norteadora aberta: "o que você percebe como aspectos positivos e negativos na sua experiência de trabalho?”. Os dados foram categorizados por meio de análise temática. Resultados: foram identificadas 4 categorias: sobrecarga e falta de informação/orientação no trabalho; a importância da remuneração; assumindo responsabilidades, esperança e superação; a vivência da doença, o cuidado com a saúde e o trabalho. O estudo mostrou a importância de buscar estratégias eficazes de inclusão laboral para indivíduos com esquizofrenia, que considerem as especificidades da doença e os fatores estressantes relacionados ao trabalho como potenciais desencadeadores de sofrimento físico e emocional. Conclusão: é fundamental investir em ações que possibilitem efetiva inclusão laboral de pessoas com esquizofrenia. Tais medidas devem contemplar os portadores de esquizofrenia, suas famílias, as empresas e os profissionais dos serviços de saúde mental. As especificidades da doença, as necessidades, os interesses e o potencial da pessoa devem ser considerados.

Palavras-chave: satisfação no trabalho; esquizofrenia; cuidados de saúde; sintomas; saúde do trabalhador.

\begin{abstract}
Objectives: to understand the positive and negative aspects of work-related experiences reported by individuals with schizophrenia who use a specialty outpatient clinic involved in a work inclusion program. Methods: observational qualitative approach study. Eleven participants answered an open guiding question: "what do you see as positive and negative in your work experience?". Data were categorized by thematic analysis. Results: four categories were identified: overload and lack of information/guidance at work; the importance of remuneration; assuming responsibility, hope and overcoming; disease experience, health and work care. The study showed the importance of seeking effective labor inclusion strategies for individuals with schizophrenia. These strategies have to consider the disease specificities and work-related stressors as potential triggers of physical and emotional distress. Conclusion: it is essential to invest in actions that enable effective labor inclusion of people with schizophrenia. Such measures should include individuals with schizophrenia, their families, the companies and mental health professionals, taking into accountthe disease specificities, the person's needs, interests and potential.
\end{abstract}

Keywords: job satisfaction; schizophrenia; health care; symptoms; occupational health. 


\section{Introdução}

Vivemos em uma sociedade na qual o trabalho é considerado uma das principais formas de organização e circulação, fazendo parte da construção da subjetividade e do lugar social das pessoas ${ }^{1}$. A possibilidade de inserir-se em uma atividade de trabalho é fundamental por proporcionar condições para satisfação das necessidades básicas, valorização de si e desenvolvimento de potencialidades ${ }^{2}$. Estar excluído do trabalho prejudica a autoconfiança, aumenta a sensação de isolamento e a marginalização ${ }^{3}$.

A importância do trabalho para as pessoas com doença mental está ligada ao envolvimento em ocupações significativas e ao impacto do trabalho no processo de recuperação, por meio da renovação da esperança, valorização da identidade, empoderamento, estabelecimento de rotinas e ampliação da capacidade de gerenciamento da doença ${ }^{4}$. No entanto, globalmente, apenas uma pequena porcentagem dessa população tem vínculo empregatício ${ }^{5}$. As baixas taxas de emprego têm sido compreendidas como o reflexo da combinação de barreiras psicológicas e sociais, como o estigma por parte dos empregadores, associadas à falta de suporte e orientação vocacional ${ }^{6}$.

Para ampliar a discussão, é importante compreender que o trabalho pode se configurar tanto como fonte de satisfação como de sofrimento, como aponta Dejours em uma entrevista publicada por Barros e Lancman ${ }^{7}$. De acordo com o autor, o trabalho impulsiona processos de subjetivação, a realização de si e a construção da saúde. Sofrimento e prazer são experiências intimamente relacionadas ao processo de trabalho e determinadas por fatores como: a organização do trabalho e a divisão das tarefas, o interesse e o sentido do trabalho para quem o desenvolve e a qualidade dos relacionamentos no dia a dia ${ }^{7}$.

Vale ressaltar que as transformações socioeconômicas ocorridas no mundo nas últimas quatro décadas tiveram um importante impacto no trabalho. Destacam-se o desemprego, a flexibilização do trabalho e a desregulamentação dos direitos trabalhistas. Desta forma, a organização do trabalho não faz parte da negociação com os trabalhadores, e sua estrutura acaba sendo definida pelo capital ${ }^{8}$.

De acordo com Lima ${ }^{9}$, as mudanças impostas ao mundo do trabalho a partir dos anos 1980 têm como resultante um novo perfil de adoecimento. Desta forma, percebe-se que, ao se transformar o modo de trabalhar, se transforma também a forma como o desgaste é vivido, ou seja, a forma como o indivíduo vive, adoece e morre ${ }^{9}$. Neste sentido, questões como a gestão pelo estresse, a intensificação do trabalho, o aumento da pressão e do controle, a competição entre os trabalhadores e a sobrecarga mental e emocional também devem ser tratadas como potenciais fontes de adoecimento ${ }^{10}$.

Tendo em vista que pessoas com doença mental possuem baixas taxas de inclusão laboral, fica evidente a importância de ações para ampliar o acesso ao trabalho. Compreender as dificuldades e as formas de viabilizar o acesso ao trabalho para proporcionar experiências positivas é estratégia fundamental de cuidado para essas pessoas. Este estudo objetiva compreender os aspectos positivos e negativos das experiências relacionadas ao trabalho e seu impacto na vida social e no tratamento, a partir do relato de usuários de um ambulatório de especialidade envolvidos em um programa de inclusão laboral. A hipótese é de que os aspectos positivos do trabalho estão relacionados à ampliação da participação social, e os negativos à sobrecarga do trabalho.

\section{Métodos}

Trata-se de um estudo de abordagem qualitativa e de natureza descritiva. Realizaram-se entrevistas abertas para acessar o conteúdo das experiências ${ }^{11}$. A utilização desse método favorece o acesso às vozes e às histórias de pessoas que normalmente permaneceriam em silêncio ${ }^{12}$.

\section{Recrutamento}

O estudo aconteceu em um ambulatório universitário da capital paulista. Entre as atividades desenvolvidas pelo serviço, havia um projeto de reinserção laboral para pessoas com esquizofrenia. Articularam-se dois estudos observacionais, um de abordagem quantitativa, que considerou os aspectos clínicos e funcionais e as relações de trabalho ${ }^{13}$, e outro de abordagem qualitativa, que examinou a dimensão experiencial dos participantes. A decisão pela realização de dois estudos independentes em vez da abordagem multimétodos justificou-se, pois a análise por triangulação de métodos ${ }^{14}$ não possibilitaria aprofundamento necessário para alcançar o objetivo desejado.

A investigação realizou-se em duas etapas, seguindo um desenho sequencial. Na primeira etapa, foi realizado o estudo de abordagem quantitativa ${ }^{13}$, que teve como critérios de inclusão o interesse do indivíduo em trabalhar, ter idade entre 18 a 45 anos, pelo menos 2 meses de estabilidade do quadro psiquiátrico e boa adesão ao tratamento. Aqueles que tinham interdição judicial foram excluídos. Esses indivíduos participaram de uma avaliação no início do estudo e, 18 meses depois, a mesma avaliação foi repetida para oferecer subsídios ao estudo quantitativo $^{13}$. Dentro do cronograma da segunda avaliação, ou seja, ao final do período de 18 meses 
de seguimento, foram pré-estabelecidos 2 dias nos quais os participantes foram convidados a responder uma pergunta aberta, para oferecer subsídios para o estudo qualitativo. Os pesquisadores pré-estabeleceram esses dias sem saber com antecedência quais seriam os participantes convocados. Este artigo descreve os resultados do estudo qualitativo.

Todas as pessoas que participaram da avaliação final da primeira etapa do estudo, nos dias pré-estabelecidos para a realização da segunda etapa, foram convidadas a responder a pergunta aberta. Todos concordaram, e foram incluídos 11 indivíduos. O estudo teve a aprovação do Comitê de Ética em Pesquisa da Universidade Federal de São Paulo (CAAE 01970312.3.0000.5505). Todos os interessados concordaram em participar do estudo e assinaram o termo de consentimento livre e esclarecido.

\section{Coleta de dados}

Foram coletados os dados sociodemográficos e ocupacionais.

A entrevista foi conduzida a partir de uma pergunta narrativa geradora ${ }^{11}$. No início da conversa, os participantes foram esclarecidos sobre o objetivo do estudo e em seguida o entrevistador propôs a seguinte pergunta: "o que você percebe como aspectos positivos e negativos na sua experiência com o trabalho?". As entrevistas foram realizadas na instituição, em um espaço reservado. Além disso, havia uma relação de confiança preestabelecida entre os entrevistadores e entrevistados, pois já se conheciam de outros grupos realizados previamente no serviço. Desta forma, foram garantidos os critérios de privacidade e conforto para a condução das entrevistas ${ }^{15}$.
Ao longo da entrevista, foram necessárias perguntas complementares, realizadas de forma a desencadear material narrativo, evitando o direcionamento do conteúdo da fala. Realizou-se um único encontro com cada participante, com duração média de 20 minutos.

As narrativas foram gravadas e posteriormente transcritas. Nomes fictícios foram usados para preservar a anonimidade dos participantes.

\section{Análise dos dados}

Os dados foram trabalhados a partir da análise temática ${ }^{16}$. Trata-se da utilização de um conjunto de técnicas de análise das comunicações para obter, por procedimentos sistemáticos e objetivos, a descrição do conteúdo das mensagens ${ }^{11}$. Para identificar os conceitos emergentes e as unidades temáticas, as transcrições foram analisadas de forma exaustiva. Foram realizados agrupamentos temáticos dos conteúdos das narrativas. Em seguida, foram analisados os temas evidenciados nos agrupamentos dos conteúdos.

\section{Resultados}

Participaram do estudo 10 homens e 1 mulher, com idades entre 23 e 45 anos. Apenas 3 pessoas não tinham completado o ensino médio, e 3 tinham ensino superior completo. A maioria era solteira e morava com a família. Apenas 3 pessoas referiram ter renda familiar inferior a 2 salários mínimos. Todos os participantes tinham diagnóstico de esquizofrenia, com média de tempo de diagnóstico de 12 anos (vide Quadro 1).

Quadro 1 Dados sócio demográficos dos participantes do estudo

\begin{tabular}{|c|c|c|c|c|c|c|c|}
\hline $\begin{array}{l}\text { Casos (nomes } \\
\text { fictícios) }\end{array}$ & Gênero & $\begin{array}{c}\text { Idade } \\
\text { (em anos) }\end{array}$ & Escolaridade & Estado civil & $\begin{array}{c}\text { Residência } \\
\text { (com quem mora) }\end{array}$ & $\begin{array}{l}\text { Renda } \\
\text { (SM) }\end{array}$ & $\begin{array}{l}\text { Tempo de diagnóstico } \\
\text { (em anos) }\end{array}$ \\
\hline Moisés & M & 23 & $\mathrm{MC}$ & Solteiro & Família & 4 a 8 & 7 \\
\hline Cássio & $\mathrm{M}$ & 28 & SC & Solteiro & Família & 4 a 8 & 13 \\
\hline Flávio & M & 43 & SC & Solteiro & Sozinho & 1 & 2 \\
\hline Francisco & M & 32 & $\mathrm{MC}$ & Solteiro & Família & $1 \mathrm{a} 2$ & 7 \\
\hline Sebastião & $\mathrm{M}$ & 38 & $\mathrm{MI}$ & Solteiro & Família & - & 24 \\
\hline Márcia & $\mathrm{F}$ & 27 & SC & Solteiro & Família & Mais de 8 & 10 \\
\hline Paulo & $\mathrm{M}$ & 44 & FC & Divorciado & Sozinho & $2 \mathrm{a} 4$ & 16 \\
\hline Wiliam & M & 30 & $\mathrm{MC}$ & Solteiro & Família & 4 a 8 & 11 \\
\hline Júlio & M & 30 & $\mathrm{MI}$ & Solteiro & Família & 4 a 8 & 5 \\
\hline Cléber & $\mathrm{M}$ & 33 & $\mathrm{MC}$ & Solteiro & Família & $2 \mathrm{a} 4$ & 10 \\
\hline Douglas & $\mathrm{M}$ & 45 & SI & Casado & Família & 1 a 2 & 26 \\
\hline
\end{tabular}

Legenda: M: Masculino; F: Feminino; FC: Ensino fundamental completo; MC: Ensino médio completo; MI: Ensino médio incompleto; SI: Ensino superior incompleto; SC: Ensino superior completo; SM: Salários mínimos. 


\section{As experiências com o trabalho}

O Quadro 2 apresenta as experiências de trabalho no momento da entrevista bem como as demais experiências ao longo da vida. Foram consideradas as atuações no mercado formal e informal de trabalho. Todos os participantes já haviam passado por alguma experiência de trabalho.

Quadro 2 Experiências de trabalho ao longo da vida e no momento da entrevista

\begin{tabular}{|c|c|c|c|c|}
\hline Nome & Experiências de trabalho & Tempo & Motivo da saída & $\begin{array}{l}\text { Situação de trabalho } \\
\text { no momento da entrevista }\end{array}$ \\
\hline \multirow{2}{*}{ Moisés } & Operador de caixa & $5 \mathrm{~m}$ & $\begin{array}{l}\text { Foi demitido por } \\
\text { corte de funcionários }\end{array}$ & \multirow{2}{*}{ Não estava trabalhando } \\
\hline & Montador de cestas de natal & $3 m$ & O trabalho era temporário & \\
\hline \multirow{3}{*}{ Cássio } & Telemarketing ativo & $3 m$ & $\begin{array}{l}\text { Não conseguiu cumprir as } \\
\text { metas e pediu demissão }\end{array}$ & \multirow{3}{*}{ Buscando oportunidades de trabalho } \\
\hline & Telemarketing receptivo & $1 \mathrm{a}$ & Foi promovido para back office & \\
\hline & Back office & $1 \mathrm{~m}$ & $\begin{array}{l}\text { Não conseguiu bater metas, } \\
\text { efeito colateral grave por uso } \\
\text { da medicação psiquiátrica }\end{array}$ & \\
\hline \multirow[t]{2}{*}{ Flávio } & Serviços gerais & $3 m$ & $\begin{array}{l}\text { Saiu porque a carga horária } \\
\text { era muito pesada }\end{array}$ & \multirow[t]{2}{*}{ Não estava trabalhando } \\
\hline & Prestou concurso & & Não passou & \\
\hline Francisco & Trabalha no comércio da família & $5 a$ & - & $\begin{array}{l}\text { Estava no mesmo trabalho, mas gostaria } \\
\text { de atuar com informática }\end{array}$ \\
\hline \multirow[b]{2}{*}{ Sebastião } & Motorista e mensageiro & $11 \mathrm{a}$ & Conseguiu um trabalho melhor & \multirow{2}{*}{$\begin{array}{l}\text { Foi interditado pela família sem seu } \\
\text { conhecimento }\end{array}$} \\
\hline & Auxiliar administrativo & 1a & $\begin{array}{l}\text { Sentiu dificuldades com a } \\
\text { realização do trabalho }\end{array}$ & \\
\hline \multirow{2}{*}{ Márcia } & Telemarketing & $6 m$ & $\begin{array}{c}\text { Não aguentou a pressão das } \\
\text { metas }\end{array}$ & \multirow{2}{*}{$\begin{array}{l}\text { Fazendo um curso de estética e } \\
\text { manicure. Buscando oportunidades de } \\
\text { trabalho }\end{array}$} \\
\hline & Vendedora de calçados & $3 m$ & $\begin{array}{l}\text { Achou muito difícil trabalhar } \\
\text { com vendas e saiu }\end{array}$ & \\
\hline \multirow{2}{*}{ Paulo } & Torneiro mecânico em MG & $11 \mathrm{a}$ & $\begin{array}{c}\text { Teve seus primeiros sintomas } \\
\text { persecutórios }\end{array}$ & \multirow{2}{*}{ Recebendo aposentadoria } \\
\hline & Torneiro mecânico em SP & $8 a$ & $\begin{array}{l}\text { Estava sintomático, saiu para } \\
\text { ficar perto da família }\end{array}$ & \\
\hline \multirow{3}{*}{ Wiliam } & Vendedor de roupas & $9 \mathrm{~m}$ & Conseguiu trabalho melhor & \multirow{3}{*}{ Aguardando perícia do auxílio-doença } \\
\hline & Vendedor de roupas & $8 m$ & $\begin{array}{c}\text { Foi demitido “por vingança do } \\
\text { gerente" (sic) }\end{array}$ & \\
\hline & Comércio da família & $15 m$ & $\begin{array}{c}\text { Deixou o trabalho depois de } \\
\text { uma briga familiar }\end{array}$ & \\
\hline \multirow{2}{*}{ Júlio } & Ajudante de serralheiro & $2 \mathrm{a}$ & $\begin{array}{l}\text { A empresa realizou uma } \\
\text { demissão em massa }\end{array}$ & \multirow{2}{*}{$\begin{array}{c}\text { Trabalhando no comércio da família e } \\
\text { dando entrada no benefício do auxílio- } \\
\text { doença }\end{array}$} \\
\hline & Balconista & $2 \mathrm{a}$ & $\begin{array}{l}\text { Fez acordo para procurar } \\
\text { trabalho melhor }\end{array}$ & \\
\hline \multirow[b]{2}{*}{ Cléber } & Auxiliar de almoxarifado & $1 \mathrm{a}$ & Foi demitido sem justificativa & \multirow[b]{2}{*}{ Ajudando o padre na igreja há 18 meses } \\
\hline & Balconista & $4 a$ & $\begin{array}{l}\text { Foi demitido por falência da } \\
\text { empresa }\end{array}$ & \\
\hline \multirow{3}{*}{ Douglas } & Porteiro no horto florestal & - & Teve sua primeira crise & \multirow{3}{*}{$\begin{array}{l}\text { Trabalhando como office boy para } \\
\text { ajudar a família há } 2 \text { anos }\end{array}$} \\
\hline & Vendedor & - & $\begin{array}{c}\text { Deixou as vendas para buscar } \\
\text { um trabalho formal }\end{array}$ & \\
\hline & Vendedor de baterias & - & $\begin{array}{l}\text { Teve uma crise e precisou de } \\
\text { internação }\end{array}$ & \\
\hline
\end{tabular}

Legenda: a: anos; m: meses. 
Com relação às experiências anteriores, a grande maioria dos postos de trabalho se caracterizava por uma baixa exigência com relação ao nível de escolaridade. Os postos de trabalho foram variados. Com relação ao tempo de permanência no trabalho, Francisco, Sebastião, Cléber e Paulo foram os únicos que se mantiveram no trabalho por um período igual ou superior a 60 meses. Júlio e Wiliam trabalharam por um tempo superior a 30 meses e inferior a 48 . Os demais trabalharam por um período inferior a 18 meses. Com relação ao motivo da saída, Cássio, Paulo e Douglas relatam que o desligamento do trabalho foi influenciado por situações direta ou indiretamente relacionadas à esquizofrenia. A dificuldade com a realização do trabalho também aparece como um dos motivos para a saída do trabalho, como é o caso de Cássio, Flávio, Sebastião e Márcia.

Com relação às experiências no momento da entrevista, observa-se que a maioria dos participantes não estava trabalhando. Entre os que estavam, a atuação estava vinculada a atividades em conjunto com a família ou em rede de suporte, como relatado por Francisco, Júlio, Cléber e Douglas. Observa-se também a busca pelos benefícios previdenciários como estratégia de acesso à renda, como é o caso de Paulo, Wiliam e Júlio. Apenas Cássio e Márcia relataram estar buscando trabalho.

\section{Discussão}

Na análise das respostas à pergunta aberta, 4 categorias emergiram como representativas da experiência dos participantes: sobrecarga e falta de informação/orientação no trabalho; a importância da remuneração; assumindo responsabilidades, esperança e superação; a vivência da doença, o cuidado com a saúde e o trabalho.

\section{Sobrecarga e falta de informação/orientação no trabalho}

A sobrecarga do trabalho traz um importante risco de adoecimento, destacando como principais fatores estressores: carga horária, exigências da função/cargo, pouco acesso aos superiores e às decisões e falta de orientação sobre as especificidades da função ${ }^{17}$.

O estresse no trabalho pode ser desencadeado por diversas situações. Com relação ao conteúdo do trabalho, destacam-se: (a) exigência no trabalho - qualidade, pressão com relação ao tempo, dificuldade em conciliar ocupação e vida privada; (b) exigência emocional - contato com público e medo; (c) autonomia - liberdade para tomar decisões sobre a execução do trabalho e a valorização e desenvolvimento de competências; (d) relações interpessoais - apoio social, violência, assédio, reconhecimento e ordens contraditórias; (e) conflito de valores e insegurança de emprego e salário ${ }^{18}$. Observam-se ainda as dificuldades com a execução da tarefa (monotonia, repetição, fragmentação, ausência de autonomia) e os riscos relacionados à execução da tarefa (risco de vida, prejuízo financeiro) ${ }^{10,18}$.

As respostas da participante Márcia sobre seu trabalho em uma loja de calçados evidenciam que o contato com experiências novas, combinado à dificuldade com o estabelecimento de relações interpessoais, pode ser assustador e trazer sentimentos como medo, ansiedade e insegurança, como mostra o relato a seguir:

\begin{abstract}
Existe um ponto que te dá um pouco de medo, ansiedade, e às vezes tem muitas pessoas que são muito tímidas também... ansiedade quando você não está acostumada com essa situação você fica um pouco mais nervosa... acontece quando estou trabalhando, que é uma situação nova, uma situação que você não conhece (...) e o medo também. (Márcia)
\end{abstract}

Quanto ao medo vivenciado pelo trabalhador, Dejours ${ }^{19}$ aponta distintas dimensões. Por exemplo, o medo relacionado ao desgaste do funcionamento mental e do equilíbrio psicoafetivo, que pode ter origem nas relações de trabalho desestruturadas, manifestando-se por meio da discriminação ou de relações de violência e de agressividade. A impossibilidade de mudança ou alívio dessa dinâmica pode originar graves problemas de saúde ${ }^{20}$.

A sobrecarga física e mental do trabalho também é relatada como uma experiência negativa, principalmente em atividades com a carga horária pouco flexível.

Cansaço físico (...) porque eu fico lá a noite toda, são os dois juntos (cansaço físico e mental)... eu trabalho das $21 \mathrm{~h}$ às $7 \mathrm{~h}$ da manhã, muito tempo, então exige os dois. (Francisco, sobre seu trabalho no mercado municipal no turno da noite)

Estou mentalmente e psicologicamente bem, mas a coluna incomoda. (Paulo, que trabalhou como torneiro mecânico por mais de 10 anos)

A simples execução de tarefas sem orientação ou a construção de algum sentido em sua realização proporciona o sentimento de insegurança e de falta de controle sobre os processos de trabalho. Essa situação é vivida como uma experiência negativa por Wiliam, que atuou em um lava a jato da família, mas se sentia inseguro por não receber as informações sobre a tarefa que deveria realizar.

Estou aprendendo a fazer um trabalho, aprendendo não, praticando, isso é um negativo... praticando é positivo, mas tem um lado negativo que não tem ninguém me acompanhando, sabe, me ensinando... fico pensando no que é certo e errado, como devo fazer... 
não tenho ninguém que me oriente lá... mas fico normal, fico pensando no que estou fazendo... O aspecto positivo seria alguém me orientar.

Eu faço (o trabalho) porque sou obrigado a ouvir que não é pra eu ficar parado, sabe o pessoal que trabalha lá, que não é para eu ficar atrapalhando, é pra eu ajudar, não sei o quê... (Wiliam)

Outra questão importante é a gestão por metas ou objetivos (gestão by stress) ${ }^{21}$. A medida pode ser uma fonte de adoecimento, tanto pela competição quanto pela ocultação de condições de doença ou pequenos acidentes como forma de priorizar as ações para atingir os resultados esperados ${ }^{22}$. As exigências relacionadas à produtividade e às metas também foram relatadas como vivências de angústia e medo.

Para eu poder trabalhar, tenho que estar $100 \%$, estou melhorando, estou chegando lá, mas às vezes me sinto inseguro... tenho medo de não executar a tarefa adequadamente. (Moisés, que não estava trabalhando e dizia que o medo de falhar o deixava inseguro)

Tive um problema no trabalho de vendas, onde eu peguei uma pneumonia. No meu exame de sangue, meus glóbulos brancos, neutrófilos e leucócitos, eles baixaram bastante, eu tive que parar o trabalho, que estava exaustivo demais, e neste trabalho teve um ponto que foi negativo que foi o fato de estar exaustivo demais. (Cássio, depois de suas experiências no telemarketing)

As experiências com a sobrecarga do trabalho evidenciam a importância de considerarmos os postos de trabalho como potenciais fontes de estresse ${ }^{17,18}$. Essa sobrecarga, contudo, não é exclusiva dos usuários dos serviços de saúde mental, pois está relacionada à estrutura do mercado capitalista ${ }^{7,23}$. No entanto, a vulnerabilidade ao estresse, característica presente em parte das pessoas com esquizofrenia ${ }^{24}$, faz com que o acompanhamento dos processos de inserção laboral favoreça a permanência no trabalho.

\section{A importância da remuneração}

A organização do trabalho no mundo ocidental está pautada no modelo capitalista, com uma grande valorização da produção e da produtividade ${ }^{25}$. Nos relatos dos participantes, a remuneração aparece como um dos fatores positivos do trabalho: "eu ganho meu dinheiro, que eu posso comer alguma coisa, assim, se eu não estiver lá em casa” (Wiliam, sobre a época que trabalhava no comércio da família).

A troca de mercadorias e valores com o meio social traz a possibilidade de autorrealização, e o retorno financeiro proporciona a retomada da confiança, favorece a autoestima e promove a independência ${ }^{25}$, como mostra o relato a seguir:

Um é que você tem seu próprio dinheiro, e o outro é que você se torna uma pessoa independente também.
(Márcia, que teve dificuldades com a função de vendedora e estava em busca de uma oportunidade de trabalho como manicure).

Curiosamente, o dinheiro nem sempre é visto como prioridade. Como foi dito anteriormente, na fala de Wiliam, receber apoio e ser acolhido ao longo da realização de uma atividade é fundamental, na medida em que valoriza a autonomia para a tomada de decisões sobre a execução da tarefa. Tais ações são apontadas por ele como tão importantes quanto o retorno financeiro:

Não é o mais importante (dinheiro), isso não é importante. Importante é aprender, entender, poder ajudar quando precisarem (Wiliam).

Vale destacar que, entre os participantes, a renda se mostrava insuficiente para atender às necessidades básicas e garantir a independência. A grande maioria morava com a família e exercia as funções de trabalho a partir de oportunidades no âmbito familiar. A renumeração é importante para maior independência financeira, para o desenvolvimento da autonomia no uso do dinheiro e para a possibilidade de configurar novos papéis sociais. O trabalho possibilita que as pessoas se tornem sujeitos ativos na sociedade, não apenas espectadores passivos dos acontecimentos externos ${ }^{4}$.

\section{Assumindo responsabilidades, esperança e superação}

Os prejuízos funcionais decorrentes da doença mental já foram bem descritos ${ }^{24}$. Anthony ${ }^{26}$ esclarece o fenômeno do recovery entre os indivíduos com doenças mentais como uma questão central no tratamento.

Cabe considerar a recuperação da doença, que se relaciona ao desfecho clínico e funcional, em contraste com a recuperação na doença, que se caracteriza por um processo contínuo e particularizado no que se refere aos aspectos internos, como insight, integração, esperança, autonomia, superação e empoderamento ${ }^{27}$. Desta forma, Silva et al. ${ }^{27}$ propõem a utilização do conceito de superação como forma de substituir o termo recovery. Os autores entendem que o termo “superação" amplia a compreensão a respeito desse processo para além da recuperação dos sintomas.

Alguns relatos trazem sentimentos positivos em relação à oportunidade de se responsabilizar pelas próprias escolhas e pelas tarefas no espaço da família, da comunidade e do trabalho. Essas conquistas acarretam o aumento da autoestima e da realização pessoal, como mostram os relatos a seguir: "tem uma hora que, na vida, você tem que se emancipar né, ter responsabilidade” (Moisés, que não estava trabalhando, mas sinalizava o fato de estar conseguindo chegar ao ambulatório sozinho como uma conquista). 
Tedesco, Martini e Villares ${ }^{28}$ destacam que ações de empoderamento incentivam o senso de autocontrole e autodeterminação ante situações compreendidas como importantes. O empoderamento é extremamente potente para o processo de superação da doença, pois favorece a confiança e a autoconfiança $^{28}$. Sebastião traz essa perspectiva em seu relato:

Em relação ao trabalho eu não estou procurando emprego ainda, então eu estou vindo de metrô, e já foi uma medalha pra mim (...) Antes eu não vinha, e isso já foi um livre arbítrio para mim; antes meu pai trazia e me buscava (...) Foi uma liberdade pra eu vir de metrô, me sentindo livre, vir de metrô e voltar de metrô pra casa.

Eu pretendo trabalhar mais pra frente, quando eu estiver mais leve, livre para voar (...) Estou cuidando da minha independência, da minha liberdade, pra depois procurar trabalho. (Sebastião)

A possibilidade de estimular novas habilidades a partir das experiências de trabalho pode ser positiva para a satisfação e para a organização em termos $\operatorname{cognitivos}^{29}$. Em nosso estudo, alguns participantes relataram que, a partir das experiências de trabalho, foi possível vivenciar situações mais produtivas e estabelecer desafios a serem superados.

Estar trabalhando, ter uma atividade para fazer, estar exercendo alguma profissão faz bem pra pessoa.

Esforço, vontade própria, querer vencer (...) Eu vou mesmo estando com preguiça (...) Venço, tem que lutar, tem que ir, não é? (Francisco, que ajudava no comércio da família havia mais de 5 anos)

Ter feito o concurso, expectativa de estudar, fazer e sentir a possibilidade de passar (...) Tenho que me superar. (Flávio, com 43 anos, decidiu prestar um concurso para um cargo público)

Estar excluído do trabalho provoca privação material, prejudica a autoconfiança, aumenta a sensação de isolamento e a marginalização. Pessoas com doenças mentais que estão desempregadas e que não têm papéis sociais significativos estão em uma posição de dupla discriminação; por um lado, ser estigmatizado por causa de seu transtorno mental e, por outro, por sua falta de ocupação ${ }^{3}$.

\section{A vivência da doença, o cuidado com a saúde e o trabalho}

Deve-se destacar que todos os participantes tinham o diagnóstico de esquizofrenia. Neste sentido, as especificidades da doença, a gravidade dos sintomas, o suporte social e as limitações na participação social devem ser considerados ${ }^{24}$. Outra questão importante é compreender como cada um vivencia a sua condição e quais são as estratégias utilizadas para lidar com o sofrimento, ou seja, aproximar-se da singularidade das experiências relacionadas ao sofrimento psíquico ${ }^{30}$. O fato de conseguir romper com o isolamento e ampliar as relações sociais pode ser extremamente benéfico, no entanto, nem sempre é uma tarefa fácil. O medo, a insegurança ${ }^{3,17}$ e o impacto da doença nas habilidades sociais ${ }^{31}$ podem ser uma importante barreira para chegar ao trabalho.

O desejo de trabalhar está muito presente entre os usuários dos serviços de saúde mental ${ }^{32}$, no entanto, a iniciativa para buscar oportunidades, por vezes, está prejudicada, parte pela sintomatologia ${ }^{29}$, parte pela insegurança de não ter sucesso, como ilustrado pelo seguinte depoimento:

[...] desânimo (...) às vezes a preguiça (...) preguiça de fazer as coisas, mas eu tenho vontade, mas a preguiça atrapalha [...] (Francisco, que trabalha com a família, mas sonha com a área da informática).

Além disso, a sobrecarga de ter uma doença crônica com uma representação social bastante negativa configura-se como uma importante barreira no acesso ao trabalho ${ }^{3}$. De acordo com Sassaki ${ }^{33}$, a acessibilidade tem a função de melhorar a funcionalidade da pessoa em desvantagem. O autor define acessibilidade como: (1) arquitetônica - eliminação de barreiras ambientais físicas; (2) comunicacional - ampliação da comunicação; (3) metodológica - utilização dos métodos para facilitar o trabalho; (4) instrumental - ampliação do acesso aos instrumentos, utensílios e ferramentas de estudo, de trabalho, de lazer e recreação; (5) programática - eliminação das barreiras embutidas em políticas públicas, normas e regulamentos; e (6) atitudinal - combate ao estigma.

O impacto social da doença traz importantes consequências para a vida produtiva ${ }^{31}$. Trata-se de uma condição de início precoce, que pode comprometer os estudos e o ingresso nas atividades de trabalho ${ }^{34,35}$. $\mathrm{O}$ retorno aos estudos nem sempre acontece, tanto pelas barreiras impostas pela vivência da doença quanto pela falta de motivação ${ }^{36}$. Cássio, que conseguiu concluir o ensino superior e viver sua primeira experiência de trabalho depois de quase 10 anos de doença, traz um relato de superação neste sentido.

\begin{abstract}
Olha, o fator mais positivo é uma evolução muito grande no meu tratamento, que eu fui internado a última vez em 2005 e, desde então, fiz faculdade e agora estou trabalhando (...) O trabalho é uma ocupação social, e dentro dos parâmetros que acho normais, parâmetros aceitos, e acho que para quem teve duas internações, de 2001 a 2005, é um sucesso muito importante para mim. (Cássio)
\end{abstract}

No estudo realizado por Catty et al. ${ }^{37}$, as experiências prévias de trabalho são apontadas como um fator preditivo para o desfecho no trabalho. Neste sentido, destacamos a fala de Júlio, um jovem de 30 anos, com 4 anos de experiência de trabalho. Ele estava ajudando nos negócios da família e valorizava 
sua experiência prévia, mas estava buscando recursos financeiros por benefício previdenciário, pois o acesso às oportunidades estava restrito.

Já tive experiências em outras empresas, já trabalhei na minha vida, em três empresas mais ou menos, e sei como é bom a gente conquistar as coisas pelo esforço (Júlio).

Outra questão é que a revelação de uma condição de doença pode diminuir o acesso ao trabalho, causar demissão, estigma ou assédio por parte dos colegas de trabalho, além dos riscos psicológicos e de saúde como resultado do estresse e da angústia ${ }^{32}$. A grande maioria dos participantes do estudo não revelou a condição de doença em suas experiências de trabalho. Tal fato pode trazer mais sofrimento às pessoas com esquizofrenia, na medida em que têm que lidar com os desafios impostos pelo trabalho somados à experiência do sofrimento psíquico de forma solitária.

\section{Limitações e particularidades positivas do estudo}

Mesmo com todos os esforços para realizar um estudo fiel aos seus objetivos, algumas limitações devem ser notadas. Trata-se de amostra de conveniência, com pessoas em fase de estabilidade da doença, bom nível de escolaridade e realizando tratamento em serviços universitários. Essas características podem conferir um contexto específico para a análise das experiências. Além disso, a sintomatologia da doença não pôde ser identificada, inviabilizando a discussão sobre os aspectos positivos e negativos relatados nas entrevistas e a sintomatologia da doença de forma individualizada. Outra questão importante é que, com exceção daqueles que trabalhavam com a família, o diagnóstico da doença não foi divulgado nas empresas, impossibilitando qualquer iniciativa de adequação da tarefa e/ou posto de trabalho por parte dos empregadores, o que mereceria atenção específica. Ademais, estudos longitudinais de maior duração poderiam apontar eventuais processos de redução e/ ou agravamento das dificuldades apontadas.

O estudo apresenta contribuições relevantes a respeito da inclusão social pelo trabalho de pessoas com transtornos mentais. Uma delas é o reconhecimento de que o trabalho tem grande potencial para desencadear processos de adoecimento, tanto no que se refere à organização quanto às exigências da tarefa. Vale destacar que a esses aspectos, já consagrados na literatura, o estudo acrescenta uma discussão válida, na medida em que sinaliza a importância de considerar esses elementos como pontos centrais em programas de inclusão laboral.

\section{Considerações finais}

É fundamental investir em ações que possibilitem efetiva inclusão laboral de pessoas com esquizofrenia, tendo em vista a importância do trabalho para a vida social. Para tanto, as especificidades da doença, as necessidades, os interesses e o potencial da pessoa devem ser considerados. Além disso, tais ações devem contemplar os usuários, as famílias, as empresas e os profissionais dos serviços de saúde mental.

Assim, este estudo pode ter várias implicações, que detalhamos a seguir. Com relação ao usuário, a importância da formação profissional deve ser destacada. Ele deve ser encorajado a definir áreas de interesse e a buscar formas de se instrumentalizar para sua realização. Além disso, a adesão ao tratamento é fundamental para garantir a estabilidade dos sintomas e um bom desempenho funcional ${ }^{24}$. Vale destacar que o trabalho não é contraindicado para indivíduos com esquizofrenia ${ }^{13}$, porém os fatores estressantes relacionados à esfera do trabalho, com o potencial de desencadear situações de sofrimento, devem ser monitorados ${ }^{17,22,38}$.

A família precisa ser participante ativa do processo. A orientação para os familiares é relevante para fortalecer a participação no tratamento e no planejamento de ações para a busca e a manutenção do trabalho.

Por parte das empresas, é importante destacar que a ampliação do acesso, normalmente impulsionada por políticas afirmativas, não deve ser o único caminho. Deve-se trabalhar no sentido de construir novas oportunidades pautadas em uma política inclusiva. No caso das pessoas com esquizofrenia, deve-se investir na acessibilidade metodológica, incluindo estratégias verbais ou não verbais para facilitar o aprendizado e o desempenho da tarefa, e acessibilidade atitudinal, para apoiar a construção de uma nova forma de compreender doença mental, combatendo o estigma através da informação e sensibilização sobre as possibilidades de superação da doença e de acessibilidade programática, buscando formas de flexibilizar as normas e políticas públicas que embasam essas estratégias ${ }^{33}$.

No que se refere aos serviços e profissionais da saúde mental envolvidos com a elaboração de propostas de reinserção social pelo trabalho, é fundamental desenvolver estratégias de apoio que possam acompanhar caso a caso por tempo indeterminado, com a intensidade definida pela necessidade de apoio tanto por parte dos empregadores quanto por parte dos usuários/funcionários ${ }^{38,39}$. Além disso, é fundamental o desenvolvimento de estratégias de formação para esses profissionais, proporcionando 
formas de intensificar a busca por parcerias e oportunidades, e para oferecer o suporte adequado ao longo do processo de colocação e adaptação no trabalho. Outra questão se refere à ampliação dos estudos sobre as adaptações necessárias para a superação de barreiras ao trabalho, bem como formas mais sistematizadas de avaliar prejuízos funcionais considerando as especificidades das doenças mentais.

Ações de combate ao estigma podem ser muito potentes em todas as ações acima citadas, principalmente as intersetoriais, que incluam as associações de familiares, associações de bairro, escolas, igrejas, entre outros ${ }^{3}$.

Finalizando, enfatizamos a importância de modelos que sustentem uma inserção profissional de qualidade, com condições de trabalho dignas e acessíveis. Tais ações podem contribuir efetivamente para o aumento da participação social pelo trabalho entre as pessoas com esquizofrenia ou outros transtornos mentais graves.

\section{Contribuições de autoria}

Martini LC elaborou o estudo, foi responsável pela realização das entrevistas, transcrição, descrição, análise dos resultados. Lussi IAO participou da elaboração do desenho do estudo, da análise de dados. Magalhães L participou da elaboração do desenho do estudo. Santos FV e Pimentel FA participaram das discussões para análise dos resultados. Petreche MB contribuiu com a realização das entrevistas e com a definição da abordagem utilizada. Fonseca AO participou das discussões para análise dos resultados. Attux C e Bressan RA participaram de todas as etapas realizadas. Todos participaram da elaboração e da aprovação da versão final do artigo e se responsabilizam publicamente pelo seu conteúdo.

\section{Referências}

1. Lancman S, Uchida S. Trabalho e subjetividade: o olhar da psicodinâmica do trabalho. Cad Psicol Soc Trab. Dez 2003;6:79-90.

2. Ministério da Saúde do Brasil. Organização Pan-Americana da Saúde. Doenças relacionadas ao trabalho: manual de procedimentos para os serviços de saúde. Brasília, DF: Ministério da Saúde do Brasil; 2001.

3. Stuart H. Mental illness and employment discrimination. Curr Opin Psychiatry. 2006 Sept;19(5):522-6.

4. Doroud N, Fossey E, Fortune T. Recovery as an occupational journey: a scoping review exploring the links between occupational engagement and recovery for people with enduring mental health issues. Aust Occup Ther J. 2015 Dec;62(6):378-92.

5. Chang L, Douglas N, Scanlan JN, Still M. Implementation of the enhanced intersectoral links approach to support increased employment outcomes for consumers of a large metropolitan mental health service. Br J Occup Ther. 2016 Apr;79(11):643-50.

6. Campbell K, Bond GR, Drake RE, McHugo GJ, Xie $\mathrm{H}$. Client predictors of employment outcomes in high-fidelity supported employment: a regression analysis. J Nerv Ment Dis. 2010 Aug;198(8):556-63

7. Dejours C, Barros JO, Lancman S. A centralidade do trabalho para a construção da saúde. Rev Ter Ocup Univ São Paulo. Maio-ago 2016;27(2):228-35.

8. Antunes R, Alves G. As mutações no mundo do trabalho na era da mundialização do capital. Educ Soc. Maio-ago 2004;25(87):335-51.
9. Lima MEA. Trabalho e saúde mental no contexto contemporâneo de trabalho: possibilidades e limites de ação. In: Vizzaccaro-Amaral AL, Mota DP, Alves G, organizadores. Trabalho e saúde: a precarização do trabalho e a saúde do trabalhador no Século XXI. São Paulo: LTr; 2011. p. 161-72.

10. Cardoso ACM. O trabalho como determinante do processo saúde-doença. Tempo Soc. Jun 2015;27(1):73-93.

11. Minayo MCS. Análise qualitativa: teoria, passos e fidedignidade. Cienc Saude Colet. Mar 2012;17(3): 621-6.

12. Owens J. Liberating voices through narrative methods: the case for an interpretive research approach. Disabil Soc. 2007 May;22(3):299-313.

13. Martini LC, Barbosa JB Neto, Petreche B, Fonseca AO, Santos FVD et al. Schizophrenia and work: aspects related to job acquisition in a follow-up study. Braz J Psychiatry. 2018 JanMar;40(1):35-40.

14. Oliveira FL. Triangulação metodológica e abordagem multimétodo na pesquisa sociológica: vantagens e desafios. Cienc Soc Unisinos. Maioago 2015;51(2):133-43.

15. Bonilha ALL, Oliveira DLLC. A entrevista na coleta de dados. In: Lacerda MR, Costenaro RGS, organizadores. Metodologia da pesquisa para a enfermagem e saúde: da teoria à prática. Porto Alegre: Moriá; 2011. p. 423-32.

16. Severino AJ. Metodologia do trabalho científico. 23a ed. São Paulo: Cortez, 2007. 
17. Seligmann-Silva E. Desgaste mental no trabalho dominado. Rio de Janeiro: Cortez, 2011.

18. Cardoso ACM. Indicadores sobre riscos psicossociais no trabalho. In: Silveira MA, organizador. Aspectos psicossociais e sustentabilidade em organizações: saúde, segurança e qualidade de vida no trabalho. Campinas: Centro de Tecnologia da Informação Renato Archer; 2014. p. 129-44.

19. Dejours C, Abdouchelli E, Jayet C. Psicodinâmica do trabalho: contribuições da escola dejouriana à análise da relação prazer, sofrimento e trabalho. São Paulo: Atlas, 1994.

20. Merlo ARC, Lapis NL. A saúde e os processos de trabalho no capitalismo: reflexões na interface da psicodinâmica do trabalho e da sociologia do trabalho. Psicol Soc. Jan-abr 2007;19(1):61-8.

21. Cataldi MJG. Stress no meio ambiente de trabalho. São Paulo: LTr; 2011

22. Simonelli AP, Camarotto JA. As políticas brasileiras e internacionais de incentivo ao trabalho de pessoas com deficiência: uma reflexão. Cad Bras Ter Ocup. 2011;19(3):333-42.

23. Neves RF, Nunes MO, Magalhães L. As interações entre os atores no retorno ao trabalho após afastamento por transtorno mental: uma metaetnografia. Cad Saude Publica. Nov 2015;31(11):2275-90.

24. Mueser KT, Deavers F, Penn DL, Cassisi JE. Psychosocial treatments for schizophrenia. Annu Rev Clin Psychol. 2013;9:465-97.

25. Lussi IAO. Trabalho, reabilitação psicossocial e rede social: concepções e relações elaboradas por usuários de serviços de saúde mental envolvidos em projetos de inserção laboral [tese]. Ribeirão Preto: Universidade de São Paulo; 2009. 171 p.

26. Anthony WA. The need for recovery-compatible evidence-based practices. Ment Health Wkly. 2001 Nov;11(42):5.

27. Silva TR, Berberian AA, Gadelha A, Villares CC, Martini LC, Bressan RA. Validação da Recovery Assessment Scale (RAS) no Brasil para avaliar a capacidade de superação das pessoas com esquizofrenia. J Bras Psiquiatr. 2017;66(1):1-8.
28. Tedesco S, Martini LC, Villares CC. Saúde mental, trabalho e terapia ocupacional: as bases do empoderamento. In: Soares MH, Bueno SMV, organizadores. Saúde mental: Novas Perspectivas. Londrina: Yendis; 2011. p. 135-149.

29. Green MF, Kern RS, Heaton RK. Longitudinal studies of cognition and functional outcome in schizophrenia: implications for MATRICS. Schizophr Res. 2004 Dec 15;72(1):41-51.

30. Assis JC, Villares CC, Bressan RA. Entre a razão e a ilusão: desmistificando a loucura. São Paulo: Segmento Farma; 2008.

31. Pinkham AE, Mueser KT, Penn DL, Glynn SM, McGurk SR, Addington J. Prejuízos social e funcional. In: Lieberman JA, Stroup TS, Perkins DO, organizadores. Fundamentos da esquizofrenia. Porto Alegre: Artmed; 2013. p. 109-46.

32. MacDonald-Wilson KL, Rogers ES, Ellison ML, Lyass A. A study of the social security work incentives and their relation to perceived barriers to work among persons with psychiatric disability. Rehabil Psychol. 2003;48(4):301-9.

33. Sassaki RK. História do emprego apoiado no Brasil. Rev Defic Intelect. Jan-jun 2014;4(6):17-8.

34. Esch P, Bocquet V, Pull C, Couffignal S, Lehnert T, Graas M, et al. The downward spiral of mental disorders and educational attainment: a systematic review on early school leaving. BMC Psychiatry. 2014 Aug 27;14(1):237.

35. Mueser KT, Salyers MO, Mueser PR. A prospective analysis of work in schizophrenia. Schizophr Bull. 2001;27(2):281-96.

36. Reddy LF, Llerena K, Kern RS. Predictors of employment in schizophrenia: the importance of intrinsic and extrinsic motivation. Schizophr Res. 2016 Oct;176(23):462-6.

37. Catty J, Lissouba P, White S, Becker T, Drake RE, Fioritti A, et al. Predictors of employment for people with severe mental illness: results of an international six-centre randomized controlled trial. Br J Psychiatry. 2008 Mar;192(3):224-31.

38. Becker DR, Drake R. A working life for people with severe mental illness. Oxford: Oxford Press; 2003.

39. Betti AP. Emprego apoiado. São Paulo: Editorial Clube de Autores; 2011. 